\title{
EL GÉNERO, UNA CATEGORÍA DE ANÁLISIS CRÍTICO QUE NOS CUENTA OTRA HISTORIA
}

\author{
Blanca Elisa Cabral y Edda O Samudio a \\ Universidad de Los Andes. MÉrida. Venezuela
}

\section{RESUMEN}

El género, como interpretación cultural de lo que significa ser y devenir hombre y mujer bajo relaciones de dominación, forma parte de la experiencia de vida en la que nos posicionamos diferencialmente según una lógica de poder entre los sexos. Comprender esta construcción cultural desde las Ciencias Sociales, ha convertido el género, en una categoría de análisis crítico que nos permite interpelar los saberes androcéntricos, a los que no escapa la Historia. En este sentido, pretendemos suscitar una reflexión en clave de género, para confrontar la Historia de América Latina que ha invisibilizado la presencia de la mujer, y hacer que nos cuente esa otra historia, plural y diversa, que comienza a emerger de las sombras silenciadas de la historia oficial.

Palabras clave: género, mujer, poder, historia

\section{ABSTRACT}

Gender, as a social construct of what it means to become and be male and female in dominating relationships, is part of the experience of life in that we choose one role or the other based on a logic of power between the sexes. Understanding this cultural construction from the perspective of the Social Sciences has changed the notion of gender into a subject for critical analysis that allows us to question the androcentric teachings from which History cannot escape. In this sense, we attempt to invoke a critical reflection centered on gender so that we may confront the History of Latin America, which has left women's presence almost invisible, and make it recount that other history, one plural and diverse, that is emerging from the silenced shadows of the official history as we know it.

Key words: gender, woman, power, history 


\section{INTRODUCCIÓN}

Hay los que sueñan que son ellos quienes hacen la historia, y hay también la vida que oye otra historia Riebermann. W.

La comprensión humana de las desigualdades sociales entre hombres y mujeres desde la perspectiva de género, supone un esfuerzo teórico/crítico para repensar/nos más allá de los estrechos límites de los estereotipos, esquemas de género, roles y pautas de comportamiento asignadas de manera fija e inmutable para cada sexo por un sistema de racionalidad dominante. De allí, la impostergable tarea de repensar las relaciones humanas bajo una ética de la convivencia democrática entre varones y mujeres, lo que pasa ineludiblemente por cuestionar los saberes sesgados y reduccionistas que nos estudian, y atraviesan comportamientos, cuerpos, mentalidades, vidas y relaciones, y que mutilan la idea de un saber sobre (y para) la vida, a los que no escapa la historia.

Desde esta visión crítica es absolutamente necesario interpelar teórica y epistémicamente la historia en tanto saber, preguntarnos, ¿de qué historia se trata?, ¿de qué tipo de saber estaríamos hablando para que fundamentara una historia de...? ¿de quién? ¿para quién?, ¿sobre quién...? Hablamos de concepciones, de paradigmas, principios, fundamentos, contextos, instituciones, y discursos, de procesos y por supuesto, de las personas sujetos de la historia, de las posibilidades de un acceso igualitario en la historia y de la apropiación equitativa de los procesos históricos. Pero, también hablamos, de las relaciones entre los sujetos de la historia y de la presencia de la mujer en la historia, pues, resulta que esas relaciones son de género, y es impensable, hablar de historia humana, de equidad, cuando uno de los dos elementos de la relación no está en la historia, o está distorsionado o solo re/presentado por la mirada masculina, es decir, por la imagen que los hombres tienen de la mujer. Y, sabemos, que la mujer ha sido la gran ausente de la historia.

"Destinadas al silencio de la reproducción maternal y casera, en la sombra de lo doméstico que no merece tenerse en cuenta ni contarse, ¿tienen acaso las mujeres una historia?... Testigos de escaso valor, alejadas de la escena donde se enfrentan los héroes dueños de su destino, a veces auxiliares, raramente actrices -, y aún entonces, sólo debido al enorme fracaso del poder-, son casi siempre sujetos pasivos que aclaman a los vencedores y lamentan su derrota, eternas lloronas cuyos coros acompañan en sordina todas las tragedias”. Duby y Perrot (2000: 21)

Sin perder de vista que la subordinación de las mujeres forma parte de la misma lógica dominante que subordina y oprime a ambos sexos, esta línea de trabajo abierta hacia la posibilidad de la mirada crítica de la alteridad, conlleva una intención política, cuando busca subvertir el orden homogéneo del discurso social revestido de una lógica de categorías absolutas, cosificadas, esenciales, naturalizadas y universalizadas de los procesos de construcción histórica, en los que reiteradamente se ignora, distorsiona, margina, excluye, opaca o empobrece la presencia femenina. 
El abordaje del tema histórico suele traer confusiones y sesgos cuando no se diferencia Historia (hechos, acontecimientos, sucesos, discursos, sujetos/as sociales, actores sociales, relaciones, prácticas, contextos, etc.) de historiografía -lo que se narra de la historia- (estudio bibliográfico de lo escrito sobre historia, sus fuentes, sus autores). En consecuencia, muchos hechos, acontecimientos y la participación de ciertos grupos sociales no aparecen registrados o si aparecen, es de forma estereotipada, encubierta, de soslayo o marginalmente. Es así como la vida de los sectores excluidos del poder y de lo público no es historiada (minorías étnicas, niños/as, jóvenes, mujeres, pobres, enfermos, inmigrantes, etc.) Al respecto, ya Asunción Lavrin (1985) señalaba que:

"Es evidente la ausencia del elemento femenino en la mayoría de la historiografía latinoamericana. Recientes estudios en Argentina, Brasil, Perú, México y Estados Unidos han comenzado a rescatar el papel de la mujer en la historia de América."

Tradicionalmente el conocimiento de la Historia se ha limitado al registro y/o recopilación de los acontecimientos que consideran importantes o relevantes quienes la escriben, y la historia está escrita predominantemente por el hombre, en el lenguaje de una cultura androcéntrica que lleva las marcas de una forma privilegiada de representación cultural e ideología masculina, haciendo omisión de la experiencia histórica de las mujeres, subsumidas en el criterio de universalidad humana. "El registro primario de lo que hacen y dicen está mediatizado por los criterios de selección de los escribas del poder." Duby Y Perrot (Ob. cit: 21)

Entendemos el poder en el sentido atribuido por Foucault, como "un modo de acción sobre las acciones de los otros, el poder se reproduce como tal en el ejercicio del poder, en sus múltiples dispositivos irradiados a todos los espacios sociales y humanos. Es la microfísica del poder (según el filósofo francés) traspasando tiempos, lugares, espacios, instituciones, personas, comportamientos, mentalidades, intimidades, relaciones, prácticas, y saberes. Como afirma García Canal (1996: 146)

"Nadie escapa a las relaciones de poder, y éstas no son únicamente violentas ni tampoco requieren consenso. El poder no sólo reprime, también incita, seduce, induce, facilita o dificulta, amplía o limita, hace más o menos posible una acción, constriñe o prohíbe, pero siempre es una manera de actuar sobre la acción de otros sujetos. En la relación hombre/mujer, es el hombre quién ejerce el poder en su condición de género masculino como dominante dentro de una concepción del mundo en torno a los valores de la masculinidad."

Se trata entonces, entre otras cuestiones pendientes, de visibilizar significados culturales asignados a la construcción de las relaciones entre los sexos, para mostrar ¿qué se sigue repitiendo y qué cambió en nuestra historia?; llamar la atención acerca de la ahistoricidad de las lecturas oficiales sobre el acontecer de nuestro pasado y vidas coti-

García, Canal M (1996) Género y dinero en la vieja ecuación del poder. Revista de género. La Ventana, No 3. Universidad de Guadalajara, México. 
dianas, mostrar los sesgos reduccionistas que empobrecen nuestra experiencia histórica, y, en particular, recuperar la historia de vida de las mujeres para contribuir a una remoción de la Historia, en la que se incorpore el género como categoría de análisis de los procesos sociales que conforman las construcciones de lo masculino y de lo femenino, para confrontar así la historia, y contribuir desde el análisis teórico crítico de género a los procesos de transformación (y democratización) de los discursos sociales que dan cuenta de la experiencia histórica de la humanidad, conformada y protagonizada por varones y mujeres.

De acuerdo a Michel Foucault (1986) $)^{2}$ entendemos por experiencia, la correlación, dentro de una cultura, entre campos del saber, tipos de normatividad y formas de subjetividad. De lo que se desprenden, según Foucault, los tres ejes que constituyen la experiencia, y que sería preciso considerar:

1. La formación de los saberes en cuanto campo de conocimiento: lo que significa hacer historia crítica de los saberes, comenzando por la revisión crítica de la historia que nos han contado.

2. Los sistemas de poder en cuanto a sus imposiciones normativas: Lo que significa entender que el saber histórico como mecanismo institucionalizado se constituye en un dispositivo y estrategia del poder.

3. Y, un modo de relación con uno mismo en cuanto individuo en el reconocimiento subjetivo de lo que somos, y ello significa historiar la vida de los actores, sus procesos de subjetivación, sus prácticas sociales y modos de relaciones entre sí, y entre varones y mujeres, como las dos partes fundantes de la experiencia humana.

\section{LA HISTORIA ESCINDIDA}

El objeto de estudio de la Historia ha sido el "hombre" (uso histórico del falso genérico como universal) El genérico utilizado como sinónimo de género humano, de ser humano, oculta gran parte de nuestra realidad, de nuestra existencia, de nuestras vivencias y hasta de nuestros aportes a la humanidad. Lo masculino, el hombre, el varón, ha sido el modelo, el paradigma de lo humano y “... aunque se presente como sexualmente neutro al pretender abarcar a los dos sexos, en realidad, nos excluye, condena así a la invisibilidad al femenino, género marcado como específico, como lo otro". Viki Ferrara (2001) Se trata de una omisión histórica que ha invisibilizado los rastros dejados por las mujeres y la exclusión de otros grupos sociales de la Historia oficial.

La exclusión histórica y social de las mujeres ha dado lugar a una historia escindida de la experiencia humana, la cual responde a una concepción de la vida social en la que con base en las diferencias biológicas entre los sexos, se construyen las desigualdades sociales entre hombres y mujeres, lo cual ha sido y es fuente de una de las mayores discriminaciones e injusticias sociales como realidad presente en las sociedades, exclusión reflejada igualmente en la constitución de los saberes científicos, siendo la historia, uno de ellos.

Tal y como afirma Lola G. Luna (1994) la producción histórica de la vida de las mujeres sigue estando lejos de la preocupación y debates que hoy todavía animan la historiografía masculina, todo esto, a pesar de que la historia de las mujeres es también la

FOUCAULT. Michel.: Historia de la Sexualidad. Vol. II. 1986. 
otra parte de la historia de la humanidad. Y, por supuesto, esta historia, incluso las historias de la vida cotidiana, hay que empezar por narrarlas, como un modo de recuperar la memoria cultural plenamente humana para una mejor comprensión de nuestro presente.

La mujer no tiene historia porque poco se sabe de ella, ha quedado fuera de la historia oficial. No obstante, tiene una historia, que sólo la mujer puede contar, mientras teje y desteje las historias del mundo que son su propia historia, porque como bien dice Marcela Serrano (1995):

Una mujer es la historia de lo pequeño, lo trivial, lo cotidiano, la suma de lo callado.

Una mujer es siempre la historia de muchos hombres.

Una mujer es la historia de su pueblo y de su raza. Y es la historia de sus raíces y de su origen, de cada mujer que fue alimentada por la anterior para que ella naciera: una mujer es la historia de su sangre.

Pero también es la historia de una conciencia y de sus luchas interiores. También una mujer es la historia de su utopía.

Es necesario por tanto repensar la historia de cara al siglo XXI, con una visión actual y renovadora acorde a la dinámica misma de las sociedades, al estallido de los paradigmas y a la transformación misma del conocimiento de lo social.

De ahí la importancia de visibilizar y reflexionar sobre esta problemática, la cual pasa por incorporar el género como categoría de análisis crítico de la historia, el cual aporta una forma diferente de mirar, revisar, investigar, interpretar, comprender y explicar las relaciones sociales entre hombres y mujeres, mediante el cuestionamiento y la deconstrucción de los fundamentos asimétricos y jerárquicos de poder con base en una relectura de las diferencias sexuales y de las relaciones de dominio/subordinación como construcción histórica, por lo tanto, no natural. No obstante, en la idea de una historia que dé cuenta de las complejidades de las relaciones sociales entre varones y mujeres, hay que:

“... enfocarse más bien a los procesos que generan, reproducen, mantienen y evalúan las diferencias y similitudes entre sexo y género. De igual manera es necesario contemplar, conjuntamente con el género, los procesos que dan lugar a las desigualdades y complejas relaciones entre etnicidad, raza, clase, edad, etcétera.” Ramos Escandón (1991: 23)

Recorrer con una mirada renovada nuestro pasado entre sus cambiantes narraciones y el mundo entre sus complejas contingencias, desenredar los modos como se construye la diferencia sexual en la historia, sus fundamentos ideológicos, epistemológicos y su vinculación con las relaciones de poder, es una manera de comprender, no sólo, sus orígenes, sino las pervivencias y transformaciones de las relaciones entre los sexos. Lo que empieza por concebir de una manera distinta al sujeto social, cercano a lo que Teresa de Lauretis $(1991 ; 233)$ se refiere cuando dice que:

"Se trata aquí de un sujeto ciertamente constituido en el género, pero no exclusivamente merced a la diferencia sexual, sino sobre todo a través 
de diversos lenguajes y representaciones culturales; un sujeto engendrado y que adquiere un género al experimentar las relaciones de raza y clase tanto como las relaciones sexuales; un sujeto que, en consecuencia, no es unitario sino múltiple y que se encuentra tan dividido cuanto en contradicción. ${ }^{3}$

Y, esto pasa también por releer desde la perspectiva de género, (entre otros aspectos) las sociedades precapitalistas, el impacto de los procesos de colonización y del imperialismo, los orígenes y efectos del capitalismo y su distancia y desarrollo del estado primitivo, las diferenciaciones e identidades de clase, las políticas de parentesco, las jerarquías de género, el intercambio de bienes y servicios, las organizaciones de trabajo de las mujeres, sus estructuras sociales y políticas, sus funciones religiosas y rituales, las estructuras de prestigio y privilegios, las ideologías de género, los procesos de socialización diferencial, las historias de vida etc. Reiter, Ortner y Whitehead, Leacock $(1991)^{4}$

Pero también pasa, y de manera insoslayable, por hacer una historia donde quepa la mujer, narrada por la mujer, no vista, imaginada, representada, imaginaria o idealizada por la mirada masculina, como un modo de recuperar la propia historia más allá de lo social. Hablamos por tanto, de una historia más allá de lo social, no en contra de lo social, como dice María Rivera Garreta (2005). Y, en el que, de modo fundamental, en el paradigma de lo social quepa una historia orientada por la metáfora del corazón, lo cual alude a la referencia que hace esta autora española, del texto de María Zambrano, Sobre el amor como creación histórica. ${ }^{5}$ Se trata entonces, de reescribir y releer una historia amorosa, que aún reconociendo las exquisitas diferencias entre los sexos, no sea una historia escindida, sea una historia en la que quepa el acontecer de la historia humana, que es la experiencia de vida de varones y de mujeres y de sus relaciones.

"Mi propuesta es escribir una historia a dos voces: dos voces distintas y asimétricas (no desiguales) en relación al intercambio libre. No, o no principalmente, en relación de contraposición dialéctica; porque los hombres son para mí, el otro sexo, no el sexo opuesto. En otras palabras, el hecho de ser mujer y hombre no es una antinomia del pensamiento sino una invitación a la curiosidad, a la mediación y a la práctica de la alteridad.

La historia es una, como es una la lengua y uno el mundo, pero ocurre que se encarna en dos sexos distintos y asimétricos: mujer u hombre”. Rivera Garreta (2005).

3 de Lauretis, es una de las estudiosas feministas que deja bien claras las diferencia entre sexo y género, explica por ejemplo, “... que género no es lo mismo que sexo - el cual es un estado natural, puesto que el género corresponde a la representación de cada individuo de acuerdo con una relación social particular. Esta relación es preexistente al individuo y se predica sobre la base de una oposición conceptual y rígida (estructural) de dos sexos biológicos.Teresa de Lauretis (1986) Tecnologías de género. En Ramos Escandón, C. (1991) El Género en Perspectiva. Pág.238. México, Universidad Autónoma Metropolitana.

4 Las referencias a est@s autor@s se encuentran la compilación que hace Carmen Ramos Escandón (1991) en el texto El Género en Perspectiva, México, Universidad Autónoma Metropolitana.

5 La autora se refiere específicamente al texto de María Zambrano. Sobre el amor como creación histórica, El pleito feminista y seis cartas al poeta Luis Álvarez-Piñer (1935-1936), "Duoda, Revista de Estudios Feministas" 23(2002) 205-218. Sobre la metáfora del corazón, Ead., La metáfora del corazón, en La Cuba secreta y otros ensayos, Madrid, Endimión, 1996,92-97) 


\section{RECUPERAR LA PROPIA HISTORIA}

Ser mujer hoy, pasa por recuperar la experiencia histórica de las mujeres, indagar nuestros orígenes, hurgar entre los pliegues de la memoria para encontrarnos varones y mujeres bajo el influjo de una cultura patriarcal, cuyo legado religioso de concepción judeocristiana nos impuso su sistema de creencias, normas de vida y organización jerárquica entre los sexos como parte de la visión fragmentaria del mundo. Y, como si emergiéramos varones y mujeres de "un bosque de senderos que se bifurcan", (por decirlo con la hermosa metáfora de Borges) nos distanciamos en dos subculturas distintas como si viviéramos en mundos separados, cada uno anclado a lo masculino y a lo femenino. Blanca Cabral $(2003)^{6}$

Las mujeres hemos sido y somos parte de la historia, y cada día hacemos la historia que vivimos, entre la rutina y el ritual de lo cotidiano. Somos el testimonio vivo de la memoria frente a la negación y opacidad de la historia oficial. Nuestra biografía personal cuenta otra historia que es testimonio de la cotidianidad en clave de mujer. De allí, que incorporar la variable género como dispositivo teórico crítico, nos permite cuestionar, confrontar e interpelar la historia oficial para deconstruirla epistémicamente.

Bien lejos de la fragmentación de los saberes, de un pensamiento único u homogénea línea de acción, pensamos que esta deconstrucción debería partir de:

- concepciones fundamentalmente abiertas y críticas, diversas, flexibles, plurales que tomen en cuenta el valor del saber para orientar y dar sentido a la experiencia de vida de los hombres y de las mujeres.

- fundamentos teórico/conceptuales y epistémico críticos, cuestionadores de lo que pensamos y hacemos $1 @$ s que estudiamos la historia, vinculados al conocimiento e investigación de nuestra realidad multidimensional, cambiante y contingente,

- una toma de posición ante los problemas esenciales: sociales, culturales, educativos, pero también del reconocimiento de los logros, avances, crisis y nuevos desafíos que nos presenta la sociedad y la cultura, en sus contextos específicos y modos de inserción en la realidad mundial.

Alrededor de estas premisas sugerimos discutir y reflexionar, partir de preguntas y de algunos problemas cruciales. Y he aquí algunas de las posibles e iniciales sugerencias (más no respuestas) que pueden ir entretejiendo los hilos para construir otras formas de ver y estudiar la historia, hoy por hoy, en que todavía nos alcanzan las astillas del estallido de los paradigmas, y en que tanto se habla de la crisis de la modernidad, con sus crisis de la razón, de la historia, de la idea de progreso, de las ciencias, de las ideologías, y además, de la incertidumbre que puede significar el futuro de la historia, pues, el mundo al que se debe la historia no ha cesado de transformarse y, con ello -la misma historia- que le acontece y la vida que es preciso historiar de una manera más equitativa, más plural y diversa.

Desde esta tarea de revisión/análisis/deconstrucción/reconstrucción y reinserción en la realidad que acontece, podemos contribuir a apoyar una historia VIVA, pues, nos toca vivir y experienciar nuestra historia de la que somos contemporáneos; una historia viva

6 Cabral, Blanca Elisa (2003) Para una Crítica a la Razón Sexual en Tiempos Vividos. Tesis Doctoral. Caracas, Universidad Central de Venezuela. FACES, UCV. 
que responda al acontecer de estos tiempos, a la dinámica misma de los cambios, a los desafíos de la necesaria y urgente revisión crítica-histórica- de la vida misma. Una historia de los cambios y transformaciones en el acontecer del presente, que no es, precisamente, la historia oficial en lo que tiene que ver con una cronología o sólo con una historiografía o de la jerarquía establecida en las historias oficializadas.

No olvidemos, que la memoria humana en su proceso cognoscitivo, interioriza la historia individual o social; como crónica de lo fragmentario o sucesión de eventos, como arqueología de la vida, historia global o; sencillamente como el testimonio de complejidad o simplicidad de vivir la historia en lo cotidiano. De allí, el significado de recordar que: "Hay los que sueñan que son ellos quienes hacen la historia, y hay también la vida que oye otra historia." Riebermann. W. (1980) Ylas mujeres (y muchos hombres también) queremos oír otra historia que dé cuenta de la diversa y compleja trama de la experiencia humana, de la que somos coparticipes y coprotagonistas de la historia que es preciso contar.

\section{CONFRONTAR LA HISTORIA A PARTIR DEL GÉNERO COMO DISPOSITIVO CRÍTICO}

Nuestra propuesta pasa por atender la formación de los saberes en cuanto campo de conocimiento: lo que significa hacer historia crítica de los saberes (disciplinas, ciencias, humanidades) vinculadas a las relaciones de género, visibilizar la presencia de la mujer en la historia y contar la historia con las mujeres como sujeto histórico.

El caso venezolano es paradigmático de esta cuestión, pues las mujeres, llevamos la misma impronta de la historia de los pueblos de América Latina: conquista, colonización, dependencia, subdesarrollo... ¡ años de dominación...! resistencia, rebelión y luchas por la independencia y la autonomía. Ser mujer latinoamericana, significa transitar la propia historia de dominación, dependencia y subordinación bajo el marcaje de la condición de género y sus efectos perversos en el en androcentrismo, machismo, sexismo, prejuicios, esquemas de pensamiento, prácticas y relaciones que es preciso develar, para conocer nuestra propia historia detrás de los efectos de superficie. Cabral, Blanca (1999) que hace que aún pervivan tras las formas de ser y de relacionarnos varones y mujeres en nuestro país. Esta especie de cartografía, que llevamos adosada a formas características de ser en Venezuela, implica atender a los sistemas de poder en cuanto a sus imposiciones normativas; y, ello, significa deconstruir los mecanismos institucionalizados en dispositivos y estrategias del poder al interior de las formas de relaciones entre los sexos en nuestro país.

$\mathrm{Y}$, finalmente, atender a un modo de relación consigo mismo en cuanto individuo, en el reconocimiento subjetivo de lo que somos, y ello significa historiar la vida de todos los actores, sus procesos de subjetivación, sus prácticas sociales y modos de relaciones entre sí, entre varones y mujeres, como las dos partes fundantes de la experiencia humana, pero también, historiar la vida de los varones entre sí y de las mujeres entre sí.

Cada vez más, parece haber un alejamiento del sentido de referente histórico, al perder la sociedad venezolana actual su capacidad de retener su propio pasado, su sentido de la historia. En este sentido cobra importancia una historia que testimonie la historia viva que no sólo crece en la memoria interior de hombres y mujeres, sino principalmente en las relaciones que se establecen entre ellos, y sabemos que esas relaciones son de género, transmiten, y reproducen género. 
Por lo tanto, tenemos que comprender las relaciones hombre mujer entre las que suele transitar y objetivarse sus mentalidades, prácticas y relaciones y, fundamentalmente, estas relaciones suelen ser prácticas, comportamientos y relaciones sociales de género, en cuanto co/existen antagónicamente junto a otros ejes de articulación del poder como los de clase, raza, etnicidad, generación, edad etc, mediante un conjunto -colectivo-de representaciones, asignaciones, divisiones, distinciones, distribuciones, roles, funciones, vínculos, valoraciones... que posicionan de modo desigual según la pertenencia a uno u otro sexo

Se trata entonces de incorporar la teoría crítica de género, como categoría de análisis en su indudable dimensión política, desde el mismo momento en que busca erosionar la ideología patriarcal, propiciar el desmontaje de determinaciones biológicas y culturales, de movilizar, impugnar, cuestionar, remover y desestructurar las condiciones que reproducen las desigualdades sociales entre los géneros, a través del cuestionamiento, interpelación, deconstrucción y desmantelamiento de las relaciones sociales desiguales entre varones y mujeres. Y, con ello, trastocar la lógica de reproducción de los sistemas de representación, que es según, Rigoberto Lanz (1991: 17) el lugar exacto donde se juega la permanencia o transformación de todas las relaciones de dominación.

El germen de los estudios de género está precisamente en activar la crítica a la racionalidad occidental, justamente, el contexto que nos permite ubicar y hacer extensivas las posibilidades (imprescindibles) de la crítica cultural a las relaciones de dominación de un sexo sobre el otro, y de contribuir al desmantelamiento de sus presupuestos androcéntricos, patriarcales y sexistas, fundamentalmente, al modo cómo se construyen las diferencias sociales "en razón" del sexo. Desde esta postura apostamos por una comprensión de lo humano en tanto persona más allá de sus diferencias de género, un sujeto que responda a la idea de comprender su transitoriedad y contingencias, a través de una revisión de nuestros modos de pensar y que nos permita repensar las relaciones sociales entre hombres y mujeres con nuevos y diferentes ejes de comprensión.

Y, ello convoca a la importante tarea de una mirada atenta, ágil, flexible, abierta a la complejidad, a la multidimensionalidad a la multiculturalidad, a la democracia, a la paz, la equidad en las relaciones sociales. Todo esto conlleva a responder a la pregunta crucial de Tourraine: ¿Podremos vivir juntos? Solo posible en democracia y, en democracia participativa, y la democracia sólo es posible si aprendemos a convivir juntos hombres y mujeres, con sus diferencias, singularidades, especificidades, tensiones y contradicciones en unidad y diversidad como parte inextricable de la experiencia humana, y a este proceso bien puede contribuir la historia a superar su propio déficit democrático. 